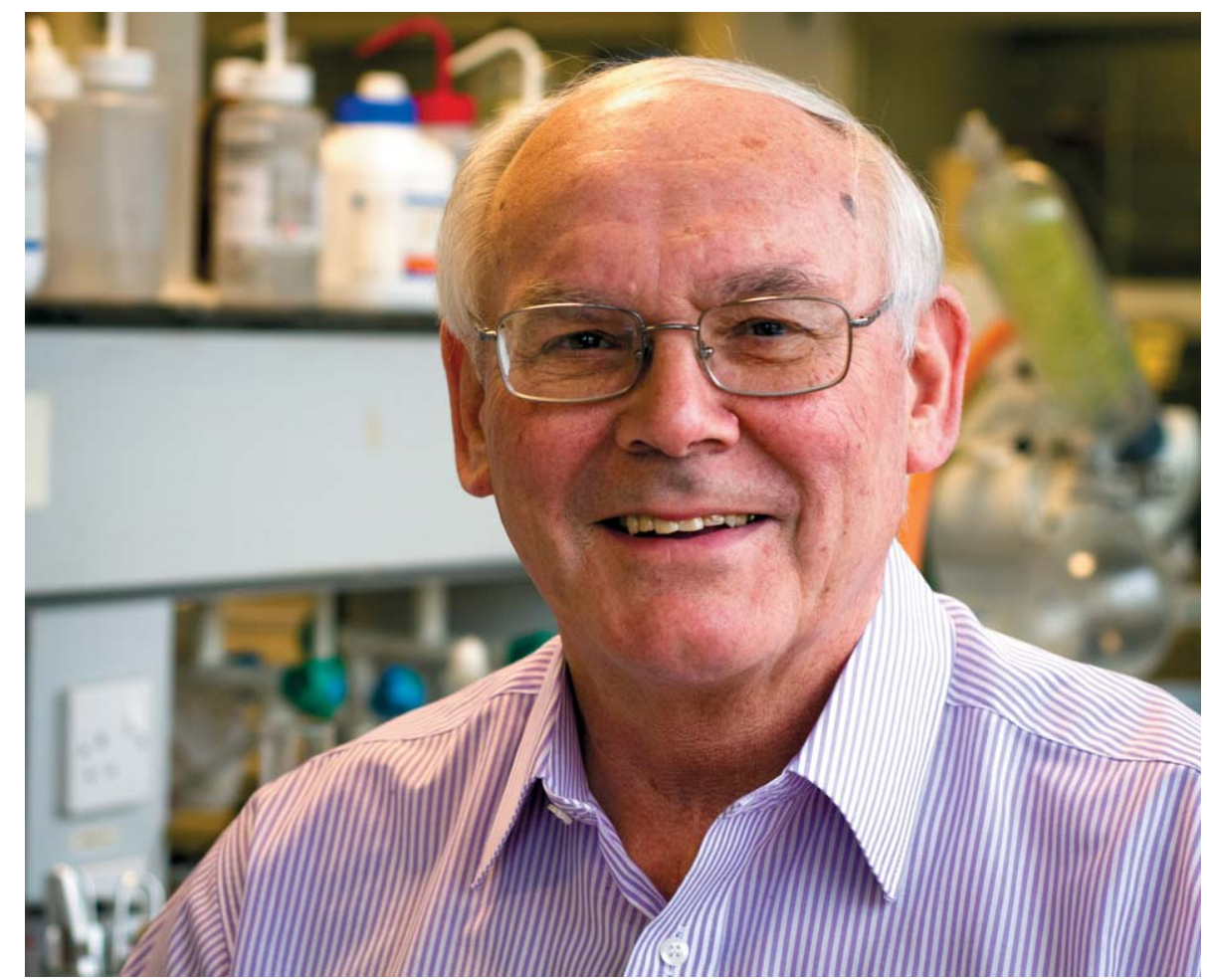

To the Contributors and Readers of this Issue of Synlett

I am very grateful to all of you who have contributed to this issue of Synlett. Indeed, I am flattered and somewhat humbled by this tribute and the attention given to me.

I feel privileged to have spent my career in academe pursuing research in synthetic organic chemistry, with natural products as the focus. Just as important has been the pleasure I have derived from working with young people who have been at a crucial time in their development. Many of these young colleagues have been an inspiration to me, as well as a great source of fun and entertainment. I sincerely hope that future generations of synthetic chemists in academe will derive as much fulfilment and enjoyment from this absorbing subject as I have over my career.

The image, let alone the practice, of synthetic organic chemistry and target natural product synthesis, has changed greatly in recent decades. I am even told that some young practitioners feel somewhat unsure, even slightly threatened by its future! Let me reassure these colleagues that this feeling is not new; my own generation felt the same pressures and threats in their formative years. I am confident that organic synthesis will remain the cornerstone, and natural products the focus, of most future developments in biosciences, materials science, medicine and molecular engineering for decades to come. Synthetic organic chemists "make and create" chemical compounds, biological materials, and molecular devices for all sorts of reasons and applications; no other scientist can boast these special and distinctive attributes!
I have often been asked, so where is it all going now (this "synthesis", and "natural products")? Well, I reply, the goals of efficiency and selectively in chemical synthesis will clearly remain a significant priority. So too will socio-economic issues like the environment, food supply and safety, and energy, among others. Developing practical asymmetric catalysis, rivalling enzymes; $\mathrm{C}-\mathrm{H}$ activation strategies; cascade reactions; and combining chemicals in a single step, will also continue to challenge. As for natural products and their synthesis, Nature has provided us with vast libraries of diverse chemical compounds over the past few billion years, but still many remain to be characterised and their biological functions determined. I have little doubt therefore that new natural product structures and their synthesis, most likely inspired by biosynthesis speculation, will remain a focus for generations to come. I am also confident that the design and synthesis of natural product-like structures and their conjugates/hybrids, fit for purpose as it were, for a wide range of important biomedical applications and molecular devices, will become an increasingly absorbing activity. It remains a very exciting time to pursue imaginative synthesis inspired by natural products.

\section{G. Pattenden}

March, 2010 


\section{SYNLETT}

\section{Editorial}

\section{Laudation for Professor Gerry Pattenden FRS}

Gerry Pattenden celebrates his seventieth birthday this month. It seems only yesterday that one of us (LMH) was interrogated by Gerry during his $\mathrm{PhD}$ viva, where an unfortunate mis-spelling of 'phthalic' in the thesis led to the inevitable Pattenden-esque comments. The other of us (CJM) has more recently had the honour and privilege in succeeding Gerry as Sir Jesse Boot Professor in Nottingham. It is therefore a particular pleasure for both of us to edit this special issue of Synlett that contains 41 papers from colleagues, past and present, former students and postdocs, and other colleagues, in recognition of Gerry's many outstanding contributions to organic chemistry.

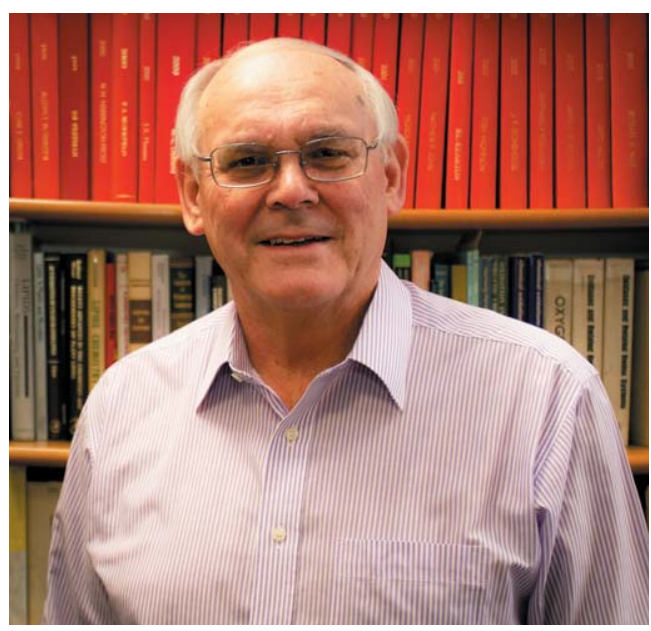

Gerry Pattenden was born in Woking, Surrey, on the 4th March 1940. Following a BSc at Brunel University in 1963 he obtained his PhD from Queen Mary College (University of London) in 1966, working with Basil Weedon (later ViceChancellor of the University of Nottingham) on carotenoids. He was appointed to a Lectureship at Cardiff University in the same year, where he quickly established an independent research career and also married Christine, one of Leslie Crombie's graduate students. Moving to Nottingham in 1972, he was promoted to Reader in 1975, Professor in 1980, and then succeeded Crombie as Sir Jesse Boot Professor in 1988. In Nottingham he served as Head of School of Chemistry for eight years and as Pro-Vice Chancellor (Vice President) for Research and Industry of the University for six years. Stepping down from the Sir Jesse Boot Chair in 2005, Gerry remained a Research Professor in Nottingham until 2009, and is now Professor Emeritus.
In addition to his University duties and extensive research programmes (see below), Gerry has always found time to be a good citizen. For example, he served as Chair of Organic Chemistry Committee of SERC - the forerunner of EPSRC (1992 - 94), as a Member of Council of The Royal Society (2001 - 03), President of Organic Division of Royal Society of Chemistry (1995 - 97), and as Scientific Editor of J. Chem. Soc. Perkin 1 (1995 - 98).

Throughout his career, Gerry Pattenden's name has been associated with the development of novel strategies for organic synthesis, intimately linked to natural products and biosynthetic processes, and to the total synthesis of a very wide range of natural products. Indeed, he has been one of the most consistently creative organic chemists of his generation, and the Pattenden group has a remarkable record of achievement in natural product synthesis, attaining a world-leading position in this internationally competitive arena.

Although the main impact of Pattenden's work has been in natural product synthesis, these endeavours have always been interwoven with structural, biosynthetic and biomimetic studies. Thus, his very early research uncovered the structures and biogenetic relationships of the striking poly-cis carotenoids found in Tangella tomatoes, and he was the first to study the biosynthesis of the novel cyclopropane terpene chrysanthemic acid found in pyrethrin insecticides. These studies blossomed into extensive structural and synthetic investigations of the steroids precursor presqualene, the carotenoids precursor prephytoene, and casbene, the cyclopropane ring containing macrocyclic diterpene precursor of such important natural products as taxane and phorbol.

Over the period 1978-1983, Pattenden's laboratory developed the use of the intramolecular de Mayo-Grob fragmentation process and other photocycloadditions in the synthesis of a wide range of important sesquiterpenoid compounds including zizaane, capnellane, hirsutane, taylorione, and pentalenene. In the mid 1980s, Pattenden began synthetic studies of the free radical chemistry of the carbon-tocobalt bond present in vitamin coenzyme $\mathrm{B}_{12}$ and its analogues. These studies culminated in a flow of publications, demonstrating the scope of the reactions in modern synthesis, including important natural product targets such as the $\beta$ lactam antibiotic thienamycin and the anti-allergic diterpene forskolin. Later work extended these studies into enantioselective synthesis involving "cobalt $\pi$-cation" intermediates, mimicking still further the novel biological role of this important coenzyme. 
Pattenden's group also pioneered the development of an impressive variety of "cascade" free radical processes, starting from polyene precursors, including multiple 6-endo-trig sequences and macrocyclisation-transannulation processes. These creative and elegant studies enabled the syntheses of many polycyclic ring systems, including a route to the taxanes and to several important natural products, e.g. oestrone, spongianone, and the propellane natural product modhephene and pentalenene. Pattenden's cascade of no less than seven 6-endo-trig radical cyclisations from a heptaene leading to an all-trans, anti, trans, heptacycle stands as a 'world record' for these types of reactions. As a result of these studies, the Pattenden group received much attention for their total synthesis of a wide variety of complex natural products, where free radicals have been the key, strategic intermediates.

In recent years, his group has received much acclaim for the total synthesis of many important targets, particularly marine natural products. These include: the tris-oxazole macrolide ulapualide from marine nudibranchs; the platelet activating factor antagonist phomactin A isolated from Phoma sp.; the proteasome inhibitor salinosporamide and the immunosuppressive agent pateamine $\mathrm{A}$; amphidinolide $\mathrm{A}$ and rhizoxin $\mathrm{D}$, both novel polyene polyol macrolides with potent anticancer properties; the complex diterpene intricarene, from corals; the oxazole/thiazoline-based natural products thiangazole and anhydropristinamycin; the unique heterocyclicbased cyclopeptides mollamide and trunkamide from seasquirts; and the marine sponge metabolite phorboxazole A, which is the most potent anti-cancer compound yet to be isolated from Nature. Many of these accomplishments represent land-marks in organic synthesis that have been achieved in hotly contested areas of international competition, and the work has subsequently attracted world wide attention.

Most recently, Pattenden has focused his studies on unravelling the biosynthetic interrelationships between furanobutenolide-based macrocyclic cembranes and a number of structurally complex polycyclic diterpenes, e.g. intricarene, beilschowskysin, plumarrelide, rameswarolide, isolated from corals. Already a total synthesis of intricarene has been accomplished involving an unprecedented transannular 1,3dipolar (oxidopyrylium-alkene) cycloaddition as the key, biomimetic, step, and an intramolecular [4+3] cycloaddition process, inspired by biosynthesis speculation, was used to elaborate the central tricyclic ring system in the related natural product rameswarolide. Pattenden's group has also uncovered a biomimetic conversion of the 14-membered ring deoxypukalide into the 12-membered ring deoxypseudoterolide by photochemical [1,3]-sigmatropic rearrangement.

Gerry Pattenden's achievements are presented in over 465 original scientific publications, and the importance of his research has been recognised in many ways. He was elected as a Fellow of The Royal Society in 1991, and has received a number of awards, including: the Corday-Morgan Medal and Prize (Royal Society of Chemistry, RSC, 1975); Simonsen Medal Winner $(R S C, 1987)$; The Tilden Lectureship (RSC,
1991); Noelting Distinguished Chair Holder (Mulhouse, France, 1991); Award in Synthetic Organic Chemistry (RSC, 1992); Award in Heterocyclic Chemistry (RSC, 1994); The Pedler Lectureship (RSC, 1995); The AG Evans Medal (University of Wales, 1995); Award in Natural Product Chemistry (RSC, 1997); Novartis Chemistry Lectureship (Basel, 1998); Hügo - Müller Award and Lectureship (RSC, 2001); Industrial Associates Award Lecture (Columbia University, USA, 2001); CNRS Award (Institut de Chimie des Substances Naturelles, Paris, France, 2000); The Gurbakhsh Singh Award (Indian Chemical Society, 2004); Robert Robinson Lectureship (RSC, 2008); Merck Research Lectureship (RSC, 2009).

Gerry Pattenden is not only an outstanding scientist, he is also an excellent teacher, and somebody who always has the students' interests at heart. After standing down as Sir Jesse Boot Professor in 2005, Gerry willingly re-entered the modular fray that is modern university teaching, communicating the excitement of organic chemistry in his inimitable way. What the txtspk generation of students make of his sense of humour is unfortunately not recorded. In addition, Gerry has served as an inspiring mentor to over $250 \mathrm{PhD}$ students and Postdoctoral Fellows, many of whom have senior positions in academe or industry, and some have contributed to this special issue. Those who spent time in the Pattenden lab will have their own recollections: the smooth dresser (those shirts and the cream suit), the casual flick of the hand to maintain the Bobby Charlton look (sorry, only older UK readers will understand), his firm belief in 'serving your apprenticeship,' his unnerving ability to know what was going on in the lab, his love of certain words (such as contemporaneous), and the five minute lab visit late in the day that offered so much advice and inspiration. Pattenden quotes abound: “.......but Dave, is it Chemistry?", "look here's a tenner - that should cover the single fare to Xxxxx" (on being told by a Nottingham student that he was considering doing his graduate work elsewhere), and, at a staff meeting, "if you don't agree with me, you lack perspective."

Although he is now Professor Emeritus, Gerry is around the Department in Nottingham most days, where he continues to write up his research, and act as a source of wise advice for young and old alike. He retains his passion for organic synthesis and an active interest in science, although undoubtedly he has more time to spend with Christine, his wife of over 40 years, and to watch soccer on TV. He can also indulge his interests in diy and in gardening - rumour has it, that he has even acquired an allotment.

We hope that the international community of chemists will join the contributors to the special issue of Synlett in wishing Gerry Pattenden a very happy seventieth birthday.

\section{Special Issue Editors}

Chris Moody (University of Nottingham)

Laurence Harwood (University of Reading)

February 2010 